Introduction

\title{
Introduction to outcomes measurement
}

\author{
Marcia J. Scherer \\ Senior Research Associate, Director of Consumer Evaluations CAT / UB, RERC-TET, 515 Kimball Tower Buffalo, \\ $N Y 14214$, USA
}

Much attention has been focused recently on assessing the outcomes of technology utilization. As streamlined services, cost cutting, and broadbased accountability have been mandated in all sectors of society, it is imperative that the value of technologies be demonstrated in order to assure their continued funding, development, and availability.

While anecdotal evidence may suffice when working with new services, techniques, and devices, our successes have made technological interventions commonplace. The growth in the number of technological products produced has resulted in lower unit costs, and the demand has risen. Thus, total dollar expenditures for technologies continue to increase.

We live in a time when we need to do more with less and stretch every dollar available to us. Unused technologies represent wasted resources as well as poor needs assessment. The time has come to optimize the process of matching person and technology. This challenge is one we must all learn to meet.

The authors of the articles in this special issue have met the challenge head-on. They have developed and pioneered means of assessing outcomes, tested those means, and written the results of their efforts for you to read, discuss, and use in

\footnotetext{
* Corresponding author. Tel.: +1 7168293141 ; fax: +1716 8293217; e-mail:mscherer@ubvms.cc.buffalo.edu .
}

developing a foundation of knowledge from which to begin your own outcomes measurement.

Outcomes are the result of an intervention. Outcomes measures are used to demonstrate that particular goals established with and for a potential user of technology have been identified and then achieved. Examples of such goals are employability, performance of activities of daily living, and the completion of educational programs.

An excellent springboard for assistive technology outcome measurement has been provided by Jean Minkel as the lead article in this special issue. Jean gives the reader the essential building blocks for a view of outcome achievement that is consumer-focused yet responsive to the demands for accountability from a variety of stakeholders.

With the building blocks in place, the subsequent discussion is divided into three parts: Outcomes of technology use for (1) functional gain, (2) education, and (3) vocational preparation and employment.

Using persons with spinal cord injuries as an example, the article by Bain, Block and Strehlow sets forth an assessment process for determining the most appropriate assistive technologies for enhanced functioning and independence. Brown broadens the assessment process to include psychological-aspects of technology use in her research on Functional Electrical Stimulation (FES) for young adults with spinal cord injuries.

The impact of technologies in education is the 
subject of three articles. Albaugh and Fayne assessed the value of technologies for students with learning disabilities. Keefe, Scherer, and McKee focused on the educational outcomes of learning via distance learning and telecommunication technologies. Sax, Fisher and Rumpian studied the educational impact of technology use in the inclusive classroom for students with severe disabilities.

The Job Accommodation Network (JAN) has accumulated considerable data on the employment success of persons with disabilities, a significant number of whom use technologies in order to perform their job tasks. Walls and Batiste analyzed some of this data in order to assess the influence of fatigue on job performance. Dowler, Hirsh, Kittle, and Hendricks used another subsample of the JAN data base to assess successful job accommodations made by employers and the characteristics of those persons for whom the accommodations were successful.

The sum total of the articles in this special issue will give the reader ample ideas for implementing an outcome measurement program that is focused on the user as well as on others impacted by technological assistance for persons with disabilities (employers, teachers, family members, insurance payors). They demonstrate that not only does technology make a difference in the functional capabilities of persons with disabilities, but technology can be shown to have ultimately enhanced users' goal attainment and quality of life achievement.

\section{Biographical Sketch}

Marcia J. Scherer, Ph.D., MPH, is Director of
Consumer Evaluations for the Rehabilitation Engineering Research Center on Technology Evaluation and Transfer in Buffalo, NY and is Sr. Research Associate, Center for Assistive Technology, University at Buffalo. Prior to this position, she served for ten years as a research associate and faculty member at the National Technical Institute for the Deaf, Rochester Institute of Technology.

Dr. Scherer has authored book chapters and many research articles on technology use, quality of life, and psychosocial influences on rehabilitation outcome. She is the author of 'Living in the State of Stuck: How Technology Impacts the Lives of People with Disabilities (Brookline Books, Second Edition, 1996) and she has co-edited two books: One with Laura A. Cushman entitled, 'Psychological Assessment in Medical Rehabilitation' (American Psychological Association Books, 1995) and one with Jan C. Galvin, entitled 'Evaluating, Selecting and Using Appropriate Assistive Technology' (Aspen Publisher, 1996).

Dr. Scherer is on the Editorial Board of Technology \& Disability, RESNA's journal Assistive Technology, and Home Health Care Dealer. She is a member of the American Psychological Association, National Rehabilitation Association, RESNA (an interdisciplinary association for the advancement of rehabilitation and assistive technologies), the American Congress of Rehabilitation Medicine, the American Association of Spinal Cord Injury Psychologists and Social Workers, the New York Academy of Sciences, and the American Educational Research Association. She is a Certified Rehabilitation Counselor and a Clinical Associate, American Board of Medical Psychotherapists. 